\title{
COMUNICAÇÃO PUBLICITÁRIA E DESIGN NO CONTEXTO DA INDÚSTRIA CULTURAL
}

\author{
Communication Design and advertising in the context of Cultural \\ Industry
}

\section{KEGLER, Alexandre José Muller}

Universidade Federal de Santa Catarina - UFSC

mullerkegler@gmail.com

\begin{abstract}
Resumo
O ser humano se distingue dos outros seres vivos por suas aptidões intelectuais e capacidades físicas que ao serem aliadas permitiram a criação de todos os objetos presentes na superfície da terra e até mesmo alguns para serem usados fora do planeta. Todo objeto criado precisa vencer a barreira das ideias e ser produzido dentro de uma lógica de aceitação cultural que tende a receber bem os objetos de costume e suas melhorias, e a desconfiar do absolutamente novo, pois tudo que é criado passa por um processo complexo de aceitação e fixação na mente das pessoa. Neste contexto o design atua como produtor de ideias e a comunicação publicitária atua como um mediador entre o produto criado e o consumidor através dos mais variados

\section{Abstract}

The human being is distinguished from other living by their intellectual skills and physical abilities which when allied enabled the creation of all objects present on the surface of the earth and even some to be used off-planet beings. Every object created must overcome the barrier of ideas and be produced within a logic of cultural acceptance that tends to welcome its usual objects and their improvements, and suspicious of absolutely new, because everything that is created goes through a complex process of acceptance and fixing the mind of the person. In this context, the design acts as a producer of ideas and advertising acts as a mediator between the consumer and the product created by a variety of means and this whole process is organized in what we might call cultural industry.
\end{abstract} meios e todo esse processo se organiza no que podemos chamar de indústria cultural.

Palavras Chave: Comunicação Publicitária. Design. Industria Cultural. Signo.

Keywords: Advertising Communication. Design. Cultural industry. Sign. 


\section{INTRODUC̣ÃO}

Desde os primórdios da humanidade o ser humano percebeu a necessidade de se relacionar com outros seres e desta relação subsidiar as mais diversas necessidades de sua vida quotidiana, trocando, vendendo ou apresentando um produto de forma a sobressair suas qualidades perante os seus defeitos com o intuito de obter resultados mais favoráveis para si.

As trocas de valores evoluíram com a humanidade e hoje são as principais geradoras das relações de compra e venda que movimentam o mercado. Estas trocas podem ocorrer em diferentes níveis, podendo ser desde relações interpessoais até as grandes estratégias de marketing e publicidade que grandes empresas fazem para atrair e fidelizar o consumidor. Desta estrutura fundamental onde tudo que existe pode se transformar em mercadoria surgiram os conceitos de publicidade e design com papeis intrinsecamente relacionados, o design como produtor de ideias necessita da publicidade para apresentar a ideia da forma correta, pois uma ideia que não é apresentada ao mundo é como se simplesmente não existisse.

\section{DESENVOLVIMENTO TEÓRICO}

A relação entre seres humanos é fundamentalmente pautada na criação e troca de produtos, e para isso será usado o conceito de produto não somente como objetos físicos, mas também como um conceito muito mais vasto e dinâmico que é possível ser aplicado a praticamente todos os campos do saber, principalmente se for observado na forma de resultado de alguma ação, ou produto de um conhecimento, gerando automaticamente a necessidade de multiplicar e ser apresentado pelo simples fato de existir.

\section{Cultura}

Biologicamente falando pode-se dizer que em condições normais todos os seres humanos são dotados de cérebro altamente desenvolvido que permite compreender as mais variadas situações e polegares opositores que Ihes permitem executar as mais diversas tarefas, porém o que diferencia um indivíduo do outro é a liberdade de escolha. Ao viver em comunidade as pessoas necessitam de regras que façam a convivência ser harmoniosa e não apenas instintiva, fazendo assim com que a existência seja diferente dos outros animais e para isso se juntam em comunidades com o intuito não só de sobreviver, mas também de justificar a própria existência através do intelecto individual. Este 
é modificado pelos diferentes contatos sociais e pode modificar o contexto cultural coletivo. Aos vários agrupamentos de interesses em comum em um determinado meio dá-se o nome de cultura.

Os indivíduos são condicionados a um modo de vida específico e particular, por meio do processo de endoculturação. Adquire, assim, seus próprios sistemas de valores e a sua própria integridade cultural. O comportamento do indivíduo é influenciado pelos padrões da cultura em que vive. Embora cada pessoa tenha caráter exclusivo, devido às próprias experiências, os padrões culturais, de diferentes sociedades, produzem diferentes tipos de personalidade, característico dos membros dessas sociedades. O padrão se forma pela repetição contínua. (LAKATOS; MARCONI, 1991, p. 136).

\section{Indústria Cultural}

Toda cultura é dotada de elementos que representam a variedade de ideias de um determinado grupo, como por exemplo, musica, arte, literatura, arquitetura, engenharia e outros, estes elementos culturais criam signos que são característicos da cultura em questão.

Cultura é um sistema de organização e entrelaçado de signos interpretáveis, compondo um contexto (de controle) das coletividades, sistema este pautado em um mecanismo de apreensão do poder por meio da posse dos signos de poder (por parte dos que controlam as altas esferas sociais) e da submissão dos seus membros. O pressuposto dessa posição é de que o "pensamento humano é basicamente tanto social como público - que seu ambiente natural é o pátio familiar, o mercado e a praça da cidade. Pensar consiste num tráfego entre símbolos significantes", que dão significado à experiência. Esses símbolos já existem antes do nascimento de qualquer ser humano e permanecem após sua morte. $\mathrm{O}$ homem se utiliza deles para construir e entender os acontecimentos pelos quais constrói sua vida (GEERTZ, 1978, p. 57)

A indústria cultural compreende esses signos e características e as transforma em mercadorias passíveis de serem reproduzidas e comercializadas. 
A indústria cultural é a integração deliberada, a partir do alto, de seus consumidores. A indústria cultural inegavelmente especula sobre o estado de consciência e inconsciência de milhões de pessoas as quais ela se dirige, as massas não são, então, o fator primeiro, mas um elemento secundário, um elemento de cálculo; acessório da maquinaria. O consumidor não é rei, como a indústria cultural gostaria de fazer crer, ele não é o sujeito dessa indústria, mas seu objeto.

As mercadorias culturais da indústria se orientam, segundo o princípio de sua comercialização. Toda a práxis da indústria cultural transfere, sem mais, a motivação do lucro às criações espirituais. A partir do momento em que essas mercadorias asseguram a vida de seus produtores no mercado, elas já estão contaminadas por essa motivação. (ADORNO, 1987, p. 288)

\section{Comunicação Publicitária}

A comunição publicitária como ferramenta de multiplicação conecta os diferentes grupos com suas diferentes características, se aproveitando da necessidade dos seres humanos de criar novas conexões neurais para modificar e facilitar suas vidas apresentando os produtos criados na indústria cultural com o intuito de criar novos signos que fidelizem o consumidor.

Quando vemos a proliferação de objetos e de marcas, de redes de comunicação e de acesso ao consumo da perspectiva dos movimentos de consumidores e de suas demandas percebemos que as regras - móveis - da distinção entre os grupos da expansão educacional e das inovações tecnológicas e da moda também intervêm nestes processos. Se alguma vez esta questão foi território de decisões mais ou menos unilaterais, hoje é um espaço de interação no qual os produtores e emissores não só devem seduzir o destinatário, mas também justificar-se racionalmente. (CANCLINI, 2008, p. 61).

Um signo só é "signo" se "exprimir ideias" e se provocar na mente daquele ou daqueles que o percebem uma atitude interpretativa. (PEIRCE apud JOLY, 1996, p. 32). 
Figura 1 - Mitsubishi Pajero Full 2009

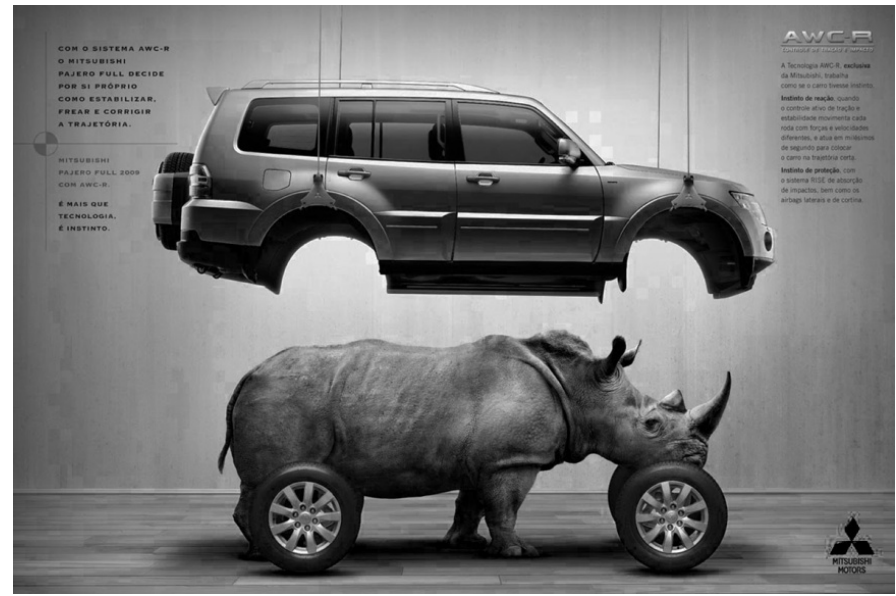

Fonte: Cardoso (2009).

\section{Design}

O design como atividade criativa se volta para a criação de produtos que representem as características de uma determinada cultura ou grupo, tentando equilibrar as necessidades do coletivo com as necessidades do indivíduo, considerando este como parte importante da totalidade.

Design é uma atividade criativa cujo objetivo é estabelecer as qualidades multifacetadas dos objetos, processos, serviços e seus sistemas durante o seu ciclo de vida. Deste modo, o design é o fator central de humanização das inovações tecnológicas e o fator crucial das mudanças culturais e econômicas. Assim, cabe ao design compreender e avaliar as relações organizacionais, funcionais e econômicas, com a missão de: garantir a ética global (por meio da sustentabilidade), social (permitindo a liberdade aos usuários, produtores e mercado) e cultural (apoiando a diversidade). Dar aos produtos, serviços e sistemas, suas formas expressivas (semiologia) e coerentes (estética) com suas próprias características e complexidades. O design está relacionado a produtos, serviços e sistemas concebidos a partir de ferramentas, organizações e processos industriais. O design é uma atividade que envolve um amplo espectro de profissões que integradas devem aumentar a valorização da vida (INTERNACIONAL COUNCIL OF SOCIETIES OF INDUSTRIAL DESIGN, 2013). 
O design por si só não é capaz de atingir o público em sua forma totalitária, ele precisa de intermediários que levem o conceito do produto criado aos consumidores pois mesmo a ideia estando materializada necessita ser apresentada ao mundo, se as pessoas não conhecem o produto, para o mercado ele simplesmente não existe.

Figura 2- Design centrado no ser humano.

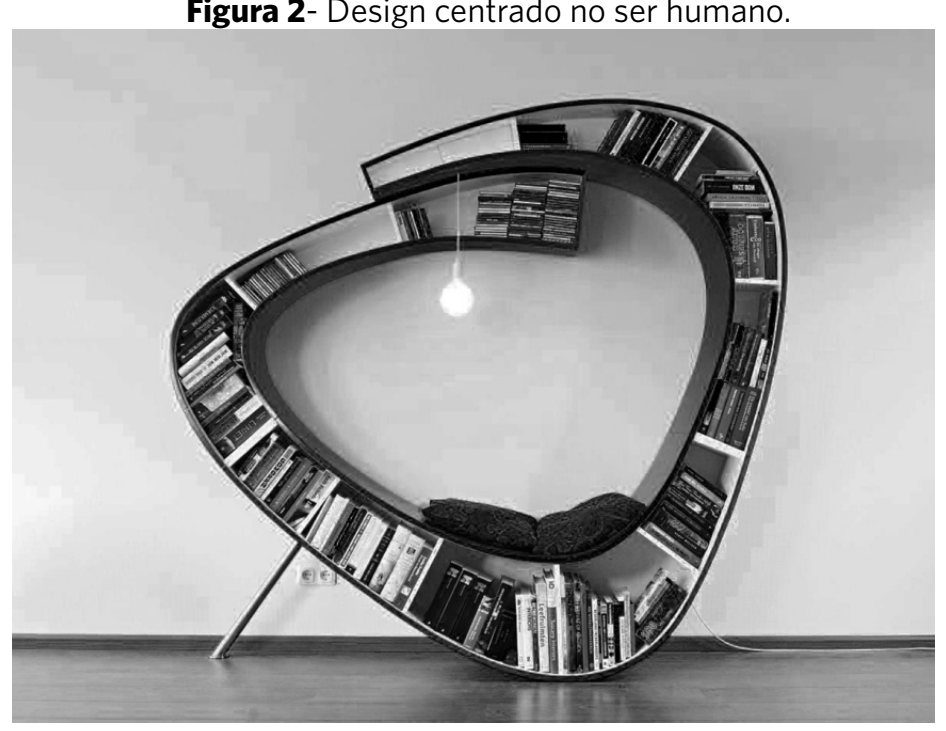

Fonte: Schirato (2013)

\section{Relação comunicação publicitária e design aplicado ao produto}

Ao analisar a linha evolutiva de determinados produtos pode-se perceber a estreita comunicação entre design e comunicação publicitária e como estes são moldados pelo meio em que o produto está inserido.

Para entender como a criação de um produto e sua comercialização estão conectados e imersos em diferentes nichos culturais foi escolhido um produto da região da grande Florianópolis a Água Mineral Imperatriz.

Fazendo um apanhado da relação da água com os seres humanos, podese dizer que todos os seres humanos precisam de água, esta é uma questão fisiológica primitiva, mas não qualquer tipo de água, precisa ser água potável para evitar doenças, uma questão de saúde, o estado de Santa Catarina com suas características regionais e culturais específicas respeita a constituição Federal do Brasil que foi criada para o povo respeitando a pluralidade cultural do país.

A constituição prevê a distribuição de água potável para todas as pessoas como um direito fundamental e o estado de Santa Catarina no cumprimento 
de leis federais disponibiliza potável para a grande maioria da população, o governo não pode arcar com as despesas de tratamento e distribuição da água então cobra tarifas da população por este serviço, transformando a água em produto.

A população que conhece a ineficiência dos serviços de tratamento e distribuição da água busca alternativas para consumir água realmente potável, abrindo um campo para purificadores de água e empresas de água mineral, esta por vir diretamente do lençol freático não tem contato com agentes poluidores e micro-organismos nocivos à saúde, gerando a cultura da água mineral.

As empresas de água mineral compreendem essa demanda e agregam valor ao produto água mineral como sendo fonte de saúde, estas empresas fazem parte da indústria da cultura à água mineral. A Água Mineral Imperatriz como sendo uma empresa de água mineral compreendeu que se o produto água é igual para todas as empresas na mente do consumidor então deveria agregar outros valores que fixassem a marca, fazendo-os preferir a Água Mineral Imperatriz em detrimento das outras marcas.

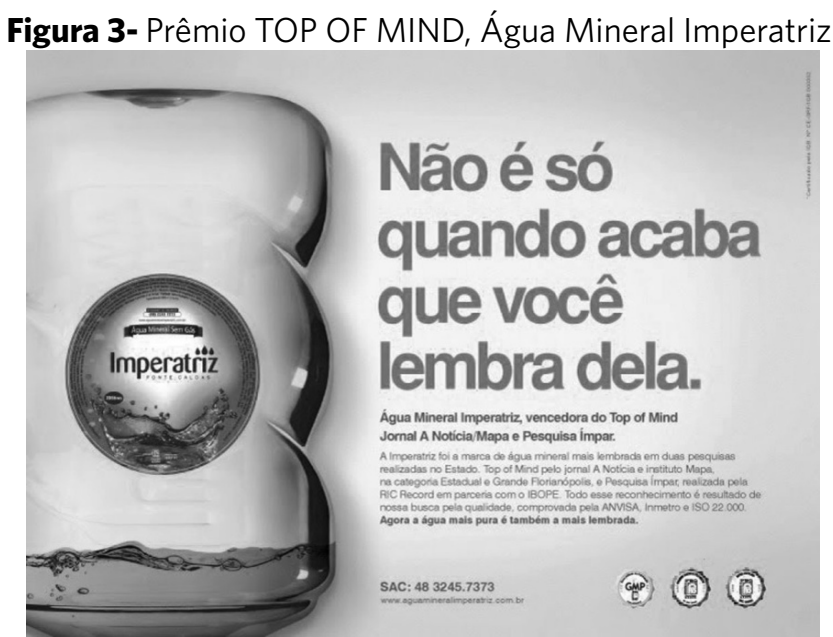

Fonte: Água Mineral Imperatriz (2010).

Em 2005 a Água Mineral Imperatriz enfrentava uma concorrência acirrada e era mal posicionada nos pontos de venda, contando com embalagens pouco atrativas. Com muitos esforços visando melhorar o seu posicionamento no mercado a empresa conseguiu se tornar a primeira água mineral do Brasil a ser certificada pelo INMETRO. Com isto a marca foi reformulada e novas embalagens para os produtos foram criadas, a capacidade produtiva foi ampliada, aumentando em $45 \%$ as vendas e em $10 \%$ os lucros.

Em 2008 a Água Mineral Imperatriz representava 50\% da participação de mercado de garrafões de 20 Litros e precisou se adequar a uma portaria do 
Departamento Nacional de Proteção Mineral que impunha prazo de validade de 3 anos para os garrafões. Dado o alto valor de fabricação dos vasilhames e a ausência de fabricantes certificados a agência de publicidade MERCADO e o cliente construíram uma estratégia que envolveu pesquisas em parceria com a empresa ESTÚDIO NUOVO DESIGN para resolver o problema de forma eficiente e diferenciada. Nestas pesquisas eles perceberam que o possível fator de diferenciação do produto era a própria embalagem e fizeram modificações no produto deixando-o mais transparente, com curvas suaves, rótulo que acompanha a posição do produto, ficando assim esteticamente mais agradável e não somente funcional. As pessoas não querem ter que esconder o vasilhame de água, elas querem mostrar para as outras pessoas como consomem produtos de qualidade superior.

A agência MERCADO compreendeu a evolução do produto dentro do contexto social e cultural e se encarregou de veicular da forma mais adequada o produto para gerar o desejo e a demanda, fizeram a comunicação por meio de propagandas e materiais gráficos. Com o slogan "Mate a Sede bonito" a empresa divulgou o novo conceito de embalagem reforçando a qualidade do produto com a garantia da certificação do INMETRO. Os resultados foram significativos já no primeiro mês com o aumento da fidelização, aumento em $10 \%$ no preço e em 12\% na participação do mercado e conquista dos prêmios Abre 2010, TOP OF MIND Revista Impar e Jornal a Notícia e o prêmio Waldemar Junqueira de "Melhor peça de Inovação".

\section{CONCLUSÃO}

Todos os conceitos apresentados anteriormente fazem parte do complexo sistema criação e veiculação dos símbolos nas culturas em geral; A cultura funciona como local ou sistema em que o processo ocorre e interfere diretamente em todas as etapas, com suas características específicas é a cultura que determina quais símbolos serão usados por este ou aquele grupo. A indústria cultural é a engrenagem principal que movimenta todo o ciclo de produção, compreendendo os símbolos criados pela cultura e transformandoos em produtos passíveis de serem comercializados.

O design compreende as necessidades e anseios do mercado apresentados pela indústria cultural e desenvolve os produtos tentando agregar os valores de acordo com as características dos grupos que as influenciam, sejam estes valores estéticos, formais, funcionais ou simbólicos, Entretanto o design por si só não consegue atrair o consumidor para o produto criado apenas com seus valores agregados, para isso se faz fundamental a participação da comunicação 
publicitária como conhecedor dos processos de veiculação e valoração das características do produto, criando no consumidor a vontade de possuir. A comunicação publicitária coloca o consumidor em contato com o produto a ser consumido através de mídias específicas para cada segmento de mercado, as quais serão mais eficientes para promover um produto de forma a sobressair suas qualidades, fazendo com que os resultados justifiquem os gastos de divulgação.

Neste sistema todas as partes são fundamentais e interdependentes e como nas primordiais relações de troca de valores o atual sistema de comércio é baseado na produção e comercialização de produtos, portanto se não houver a necessidade não haverá demanda e onde não há demanda não há produção.

\section{REFERÊNCIAS}

ADORNO, T. W. A Industria Cultural. São Paulo: Queiroz, 1987.

ÁGUA MINERAL IMPERATRIZ. Prêmio TOP OF MIND. 2010. Disponível em: <http://aguamineralimperatriz.blogspot.com.br/2010_08_01_ archive.html>. Acessado em: 18 jun. 2013.

CANCLINI, N. G. Consumidores e cidadãos. Rio de Janeiro: UFRJ, 2008.

CARDOSO, Clístenes. Mitsubishi Pajero Full 2009. Jornal Alo, Brasília, 6 maio 2009. Disponível em:<http://galodoporao.blogspot.com. br/2011/02/brasil-onde-publicidade-se-sente-em.html>. Acessado em: 18 jun. 2013.

GEERTZ, C. A interpretação das culturas. Rio de Janeiro: Zahar Editora, 1978.

INTERNACIONAL COUNCIL OF SOCIETIES OF INDUSTRIAL DESIGN. Definition of design. 2013. Disponivel em:<http://www.icsid.org/about/ about/articles31.htm?query_page=1.>. Acesso em: 16 jun. 2013.

JOLY, M. Introdução à análise da imagem. Campinas: Papirus, 1996.

LAKATOS, E. M.; MARCONI, M. D. A. Sociologia Geral. São Paulo: Atlas, 1991.

SCHIRATO. Design centrado no ser humano. Disponível em: <http://www. schirato.net/design-centrado-no-ser-humano/>. Acessado em: 18 jun. 
2013.

Recebido em: 19/08/2013

Aceito em: 17/12/2013 